\title{
Prognostic value of geriatric nutritional risk index for aspiration pneumonia: a retrospective study
}

\author{
Taisuke Araki ${ }^{1}$, Yoshitaka Yamazaki ${ }^{2}$, Norihiko Goto ${ }^{3}$, Yuko Takahashi ${ }^{2}$, Yuichi Ikuyama ${ }^{3}$, \\ and Makoto Kosaka ${ }^{2}$ \\ ${ }^{1}$ Shinshu Daigaku \\ ${ }^{2}$ Nagano Prefectural Shinshu Medical Center \\ ${ }^{3}$ Shinshu Daigaku - Asahi Campus
}

May 8, 2021

\begin{abstract}
Background/Objectives: The clinical characteristics and prognostic factors of aspiration pneumonia remain poorly defined. Geriatric nutrition risk index (GNRI) has recently been reported to exhibit a prognostic value for several diseases in older adults. Thus, we aimed to investigate the clinical characteristics and prognostic significance of GNRI for aspiration pneumonia in a sample of older adult patients. Design: Retrospective observational cohort study. Setting: Single-institute acute-phase community hospital. Participants: Patients with aspiration pneumonia diagnosed at our institute between April 2014 and March 2016. Measurements: Data on patient characteristics, microbiological findings, and clinical course were extracted from electronic medical records. The primary outcome was in-hospital mortality. Receiver operating characteristic curve (ROC) analysis was conducted to compare the predictive value of each parameter. Logistic regression analysis was performed to identify independent prognostic factors. Results: Overall, 587 patients with aspiration pneumonia aged [?] 65 years were enrolled. The mean age was 86 years. Among the patients, 97 patients (16.5\%) died. ROC analysis for in-hospital mortality revealed that GNRI had a greater area under the curve value than albumin, body mass index, and A-DROP score, with a significant difference between GNRI and albumin $(\mathrm{p}=0.0058)$. Male gender sex (odds ratio $[\mathrm{OR}]: 1.88, \mathrm{p}=0.028$,), chronic heart failure $(\mathrm{OR}$ : $2.14, \mathrm{p}=$ 0.023), history of malignancy (OR: 2.66, $\mathrm{p}=0.0025)$, lower GNRI (OR: 0.94, p < 0.001), and initial antibiotic change (OR: $4.22, \mathrm{p}<0.001)$ were identified as independent adverse prognostic factors in the multivariate analysis. Conclusion: Our findings indicate that GNRI is a potential prognostic marker for older adults with aspiration pneumonia and may act as a proxy for disease severity. Our results support the use of GNRI in the clinical management of aspiration pneumonia.
\end{abstract}

Prognostic value of geriatric nutritional risk index foraspiration pneumonia: A retrospective study

\section{ABSTRACT}

Background/Objectives : The clinical characteristics and prognostic factors of aspiration pneumonia remain poorly defined. Geriatric nutrition risk index (GNRI) has recently been reported to exhibit a prognostic value for several diseases in older adults. Thus, we aimed to investigate the clinical characteristics and prognostic significance of GNRI for aspiration pneumonia in a sample of older adult patients.

Design: Retrospective observational cohort study.

Setting: Single-institute acute-phase community hospital.

Participants: Patients with aspiration pneumonia diagnosed at our institute between April 2014 and March 2016. 
Measurements : Data on patient characteristics, microbiological findings, and clinical course were extracted from electronic medical records. The primary outcome was in-hospital mortality. Receiver operating characteristic curve (ROC) analysis was conducted to compare the predictive value of each parameter. Logistic regression analysis was performed to identify independent prognostic factors.

Results : Overall, 587 patients with aspiration pneumonia aged [?] 65 years were enrolled. The mean age was 86 years. Among the patients, 97 patients (16.5\%) died. ROC analysis for in-hospital mortality revealed that GNRI had a greater area under the curve value than albumin, body mass index, and A-DROP score, with a significant difference between GNRI and albumin $(\mathrm{p}=0.0058)$. Male sex (odds ratio $[\mathrm{OR}]: 1.88, \mathrm{p}=$ 0.028 ), chronic heart failure (OR: $2.14, \mathrm{p}=0.023$ ), history of malignancy (OR: 2.66, $\mathrm{p}=0.0025)$, lower GNRI (OR: 0.94, $\mathrm{p}<0.001$ ), and initial antibiotic change (OR: 4.22, $\mathrm{p}<0.001)$ were identified as independent adverse prognostic factors in the multivariate analysis.

Conclusion : Our findings indicate that GNRI is a potential prognostic marker for older adults with aspiration pneumonia and may act as a proxy for disease severity. Our results support the use of GNRI in the clinical management of aspiration pneumonia.

\section{What's already known about this topic?}

Undernutrition is known as a negative prognostic factor for several diseases in the elderly.

Recently, the prognostic value of GNRI has been reported in several types of disease.

\section{What does this article add?}

GNRI is an independent prognostic factor for elderly patients with aspiration pneumonia.

Key words : aspiration pneumonia; geriatric nutritional risk index; undernutrition

\section{INTRODUCTION}

Aspiration pneumonia is a clinical syndrome that often develops in patients with impaired swallowing function and cough reflex or those with underlying diseases associated with dysphagia such as cerebrovascular diseases, dementia, and Parkinson's disease. ${ }^{1}$ Concomitant with aging of the population, the incidence of aspiration pneumonia in older adults is increasing and is associated with higher mortality rates. Indeed, aspiration pneumonia accounts for $70 \%$ of pneumonia in patients aged [?]70 years. ${ }^{2}$ Despite its high morbidity and mortality, clinical features and prognostic factors for aspiration pneumonia in older patients remain poorly defined.

Current clinical guidelines for pneumonia emphasize optimal antibiotic strategies based on estimated causative pathogens. ${ }^{3-5}$ Based on these guidelines, the location of infection and several risk factors are utilized to determine the appropriate treatment strategy and prognostic evaluation. Nevertheless, these algorithms may be unsuitable for patients with aspiration pneumonia owing to the heterogeneity of this patient population. ${ }^{6}$

Older adults commonly experience nutritional issues associated with declining organ and physical functions, underlying diseases, and inadequate dietary habits. ${ }^{7}$ In hospitalized settings for older individuals, undernutrition is associated with poor clinical outcomes such as longer hospital stay and higher mortality rate. ${ }^{8,9}$ Thus, in geriatric clinical practice, the assessment of nutritional status is crucial for improving prognosis and anticipating subsequent clinical course. The geriatric nutritional risk index (GNRI) is a simple and objective index proposed by Bouillanne et al. to evaluate nutritional risk in hospitalized older patients. ${ }^{10}$ GNRI was recently reported to be a useful tool for predicting mortality in older patients with hemodialysis,${ }^{11}$ heart failure, ${ }^{12}$ various cancers ${ }^{13-15}$ and trauma. ${ }^{16}$ Wei et al. reported that GNRI demonstrated superior predictive value for poor prognosis compared with other inflammatory indicators in older patients with severe community-acquired pneumonia (CAP). ${ }^{17}$ Nevertheless, the prognostic utility of GNRI in older patients with aspiration pneumonia remains unclear. Therefore, this study aimed to investigate the prognostic utility of GNRI in older patients with aspiration pneumonia. 


\section{METHODS}

\section{Study population and patient settings}

This study was approved by the Institutional Review Board of Nagano Prefectural Shinshu Medical Center (approval no: ShinshurinriR3-2, Suzaka City, Japan). As this was a retrospective analysis, informed consent was not required to participate in the study. This retrospective study was conducted at a single facility (an acute-phase community hospital with 300 beds). We extracted the medical records of patients aged [?] 65 years who were hospitalized at our institution between April 2014 and March 2016 and who were diagnosed with aspiration pneumonia as their primary disease. We selected patients who met the criteria of CAP according to the clinical guidelines of the American Thoracic Society and Infectious Disease Society of America. Patients with hospital-acquired pneumonia (HAP) (Figure 1) were excluded. ${ }^{3}$ The diagnosis of aspiration pneumonia was defined based on clinical symptoms indicative of pneumonia (i.e., cough, sputum, and fever), infiltration on chest imaging (chest X-ray or computed tomography), and findings of aspiration assessed by a trained speech therapist (ST) and/or nurse in rehabilitation programs.

\section{Data collection}

Patient data were extracted from electronic medical records. Data on patient characteristics such as age, sex, location of residence, underlying comorbidities, body mass index (BMI), A-DROP score, GNRI score, and laboratory test results were collected. The A-DROP scoring system proposed by the Japan Respiratory Society was employed to assess disease severity. The A-DROP score consists of the following items: age [?]70 years for male individuals and [?]75 years for female individuals, blood urea nitrogen (BUN) [?]21 $\mathrm{mg} / \mathrm{dL}$ or dehydration, oxyhemoglobin saturation measured using pulse oximetry [?]90\% or partial pressure of oxygen in arterial blood [?]60 $\mathrm{mmHg}$, confusion, and systolic blood pressure [?]90 $\mathrm{mmHg}$. Depending on the number of corresponding items, 0 points was defined as mild, 1-2 points as moderate, 3 points as severe, and 4-5 points as most severe. ${ }^{18}$ Sputum samples were collected at admission to identify causative pathogens of aspiration pneumonia. They were obtained by expectoration or catheter suction and then cultured. We defined methicillin-resistant Staphylococcus aureus, Pseudomonas aeruginosa, Acinetobacter baumannii ,Stenotrophomonas maltophilia, and extended-spectrum $\beta$-lactamase-producing gram-negative bacilli as potential drug-resistant $(\mathrm{PDR})$ pathogens. GNRI was calculated as follows: $(14.89 \times$ serum albumin $[\mathrm{g} / \mathrm{dL}])+(41.7 \times$ [actual body weight/ideal body weight] $)$. Ideal body weight was calculated as: height $(\mathrm{cm})-100-([$ height -150$] / 4)$ for men and height $(\mathrm{cm})-100-([$ height -150$) / 2.5]$ for women. Nutritional risk was determined using GNRI scores, wherein GNRI $<$ 82, 82 [?] GNRI $<$ 92, 92 [?] GNRI < 98, and GNRI [?] 98 indicated severe, moderate, mild, and no risk, respectively. ${ }^{10}$ We collected data regarding initial antibiotic agents, days of administration, and switching of the initial drug to a different drug. Data on clinical course and outcomes included length of stay (LOS) and in-hospital mortality. The study endpoint was defined as in-hospital mortality. Patients who were discharged were defined as the "survivor group" and those who died during hospitalization were defined as the "non-survivor group." Patient characteristics, microbiological findings, and clinical course were compared between survivor and non-survivor groups.

\section{Statistical analysis}

Intergroup comparisons of continuous variables were performed using Student's t-test or the Mann-Whitney $\mathrm{U}$ test. Comparisons of nominal variables were performed using the chi-square test or Fisher's exact test. A receiver operating characteristic (ROC) curve was constructed using GNRI, serum albumin level, BMI, and A-DROP score as the test variables and in-hospital mortality events as the state variables. The area under the ROC curves (AUCs) was used to compare the predictive value of GNRI, albumin level, BMI, and A-DROP score. Logistic regression analysis was performed to identify significant variables for inhospital mortality. Statistically significant variables were used in the univariate model, and clinically relevant variables were further analyzed using multivariate analysis. All statistical analyses were performed using EZR (Saitama Medical Center, Jichi Medical University, Saitama, Japan), a graphical user interface for R (The R Foundation for Statistical Computing, Vienna, Austria). ${ }^{19}$ Statistical significance was set at $\mathrm{p}<$ 0.05 . 


\section{RESULTS}

\section{Patient characteristics}

Data of 634 patients with aspiration pneumonia were collected throughout the study period. Ten patients with HAP, 24 patients aged $<65$ years, and 13 patients with insufficient data for GNRI were excluded, resulting in a total of 587 eligible patients (Figure 1). Patient characteristics are presented in Table 1. The mean age of patients was $86+-9.5$ years. The study sample comprised $358(61 \%)$ male individuals and $229(39 \%)$ female individuals. More than half of the patients had lived in a nursing home $(50.1 \%)$ before admission. Among underlying comorbidities, dementia had the highest prevalence (48\%). The mean LOS tended to be longer than the antibiotic administration period ( $29.9+-24$ vs. $10.8+-6.6$ days). Among the patients, 97 (16.5\%) died during hospitalization. Regarding the information of antibiotic treatment (Table 1), ampicillin/sulbactam (ABPC/SBT) was the most frequently administered initial antibiotic (85\%), followed by piperacillin/tazobactam (PIPC/TAZ) (9.2\%). Initial antibiotics were switched to other agents in 112 (19.1\%) patients. The results of clinical parameters and laboratory tests are also presented in Table 1. The mean BMI and GNRI were $18.2+-3.6 \mathrm{~kg} / \mathrm{m}^{2}$ and $83.4+-12.9$, respectively. Among the patients, $88 \%$ were considered to have nutrition risk $($ GNRI <98) and $279(47.5 \%)$ were considered to have severe risk (GNRI <82) based on GNRI definitions. Microbiological findings are presented in Table 2. Sputum tests were conducted for 521 (88.8\%) patients. PDR pathogens were isolated from 156 (29.9\%) patient samples.

\section{Comparison of the survivor and non-survivor groups}

A comparison of the survivor and non-survivor groups is presented in Tables 1 and 2. The prevalence of chronic heart failure (CHF) and history of malignancy was significantly higher in the non-survivor group than in the survivor group ( $\mathrm{p}=0.033$ and $\mathrm{p}<0.001$, respectively). The mean GNRI score was significantly lower in the non-survivor group than in the survivor group $(\mathrm{p}<0.001)$, with $72(74.2 \%)$ patients identified as having severe nutrition risk (GNRI <82). Serum BUN and albumin levels were significantly lower and the A-DROP score was significantly higher in the non-survivor group than in the survivor group (BUN: $p$ $=0.039$, albumin: $\mathrm{p}<0.001$, A-DROP: $\mathrm{p}<0.001$ ). ABPC/SBT was more frequently administered as an initial treatment regimen in the survivor group than in the non-survivor group $(p=0.044)$. The frequency of first-choice PIPC/TAZ exhibited a trend to be lower in the survival group than in the non-survival group (survivor vs. non-survivor: $8.2 \%$ vs. $14.4 \%$ ), but this did not reach significance $(\mathrm{p}=0.056)$. The frequency of initial antibiotic change was significantly higher in the non-survivor group than in the survivor group (p $<0.001)$. No significant between-group difference was observed in the isolation rate of specific pathogens, including PDR pathogens (Table 2).

\section{ROC analysis and comparison of predictive ability}

Using in-hospital mortality events as an endpoint, AUC values were employed to compare the predictive ability of GNRI with that of other items (Figure 2). GNRI exhibited a greater AUC for in-hospital mortality (AUC: 0.718 ) than serum albumin level (AUC: 0.673), A-DROP score (AUC: 0.644) and BMI (AUC: 0.69) with a significant difference when compared with albumin $(\mathrm{p}=0.0058)$.

\section{Multivariate analysis}

The results of the logistic regression analysis for in-hospital mortality events are presented in Table 3. Male sex (odds ratio [OR]: 1.71, 95\% confidence interval [CI]: 1.07-2.75, $\mathrm{p}=0.026]$ ), CHF (OR: 1.79, 95\% CI: 1.04-3.07, $\mathrm{p}=0.034$ ), history of malignancy (OR: 2.46, 95\% CI: $1.24-4.24, \mathrm{p}=0.0012$ ), lower albumin level (OR: 0.35, 95\% CI: 0.24-0.53, p < 0.001), higher BUN level (OR: 1.02, 95\% CI: 1.01-1.04, p < 0.001), higher A-DROP score (OR: 1.76, 95\% CI: 1.4-2.21, p < 0.001), lower GNRI (OR: 0.94, 95\% CI: 0.92-0.95, p < 0.001 ), and initial antibiotic change (OR: 4.32, 95\% CI: 2.69-6.95, p < 0.001) were identified as significant prognostic factors in the univariate analysis. Male sex (OR: 1.88, 95\% CI: 1.07-3.31, p = 0.028), CHF (OR: 2.14, 95\% CI: 1.11-4.12, $\mathrm{p}=0.023$ ), history of malignancy (OR: 2.66, 95\% CI: $1.41-5, \mathrm{p}=0.0025$ ), higher A-DROP score (OR: 1.48, 95\% CI: 1.16-1.9, p =0.002), lower GNRI (OR: $0.91,95 \%$ CI: 0.87 to $0.95, \mathrm{P}<0.001$ ), and an initial antibiotic change (OR: 4.22, 95\% CI: 2.48-7.19, $\mathrm{p}<0.001$ ) were identified as 
independent adverse prognostic factors in the multivariate analysis.

\section{DISCUSSION}

The present study was conducted to assess the prognostic utility of GNRI in patients with aspiration pneumonia, mainly comprising older individuals. Multivariate analysis revealed that male sex, a history of CHF and malignancy, disease severity evaluated using the A-DROP scoring system, lower GNRI score, and an initial antibiotic change were negative prognostic factors. To the best of our knowledge, this is the first study demonstrating the prognostic value of GNRI in patients with aspiration pneumonia.

Aging is an irreversible biological process characterized by decreased organ system reserve and weakened homeostatic control. ${ }^{20}$ In older adults, these changes may lead to decreases in food intake and absorption caused by impaired gastrointestinal function, resulting in undernutrition. Furthermore, underlying disease and inadequate dietary habits may negatively affect nutritional status. Consequently, undernutrition leads to decreased activity and weakened immune function, resulting in the further deterioration of organ function and nutritional status. ${ }^{21}$ Undernutrition is associated with weakening of swallowing muscles and skeletal muscles and is a significant risk factor for aspiration pneumonia. ${ }^{6}{ }^{21}$ Several studies have reported the utility of serum albumin levels and BMI as prognostic factors for older patients with pneumonia. ${ }^{23-26}$ Nevertheless, despite the ease of evaluating these indicators, they may be influenced by various factors.

This study demonstrated that lower GNRI was a significant prognostic factor for older patients with aspiration pneumonia. GNRI is calculated based on serum albumin levels and a physique-based index. This nutrition-related index is easily assessed without the need for complex procedures such as the measurement of grip strength or limb circumference. Our ROC analysis indicated that the AUC value for GNRI was greater than that for albumin and BMI, and a significant difference was observed with albumin. Serum albumin is affected by extracellular fluid volume, dehydration status, and inflammatory dynamics. ${ }^{27} \mathrm{BMI}$, a physique-based index, is also affected by recent dehydration status. Thus, GNRI, which is derived from serum albumin levels, height, and body weight, may have optimized the deviation caused by these factors.

Recent studies have highlighted the prognostic significance of GNRI in various diseases. According to seminal reports, GNRI $<98$ was defined as nutrition risk. ${ }^{10}$ In our cohort, more than $70 \%$ of patients had GNRI $<98$ (even in the survivor group), suggesting that most patients with aspiration pneumonia in our cohort were at nutritional risk. Thus, establishing a cut-off value for GNRI in patients with aspiration pneumonia is critical and warrants resolution.

The multivariate analysis revealed several independent prognostic factors other than GNRI, including male sex, CHF, history of malignancy, and higher A-DROP score. CHF is a risk factor for hospitalization with pneumonia. ${ }^{28}$ In patients with heart failure, alveolar flooding may disrupt immune function in the alveoli, including effective opsonization and macrophage function, consequently affecting microbial clearance and increasing the risk of pneumonia. ${ }^{29}$ In addition, patients with impaired cardiac function may fail to meet the increased demand for cardiac output owing to hemodynamic changes associated with pneumonia. ${ }^{30} \mathrm{~A}$ current or latent history of malignancy can adversely affect the clinical course of patients with aspiration pneumonia. Cancer-related inflammation causes exhaustion, which leads to undernutrition and inactivity. Systemic cytotoxic chemotherapy or radiotherapy may attenuate immunity owing to impaired bone marrow function, dysfunction of immunocytes, and prolonged gastrointestinal dysfunction. The prognostic utility of scoring systems such as CURB-65, A-DROP, and pneumonia severity index for older patients with pneumonia remains controversial owing to heterogeneity in older adults. ${ }^{31-33}$ These scoring systems comprise age, gender, vital signs, laboratory findings, and comorbidities but lack nutritional indicators. Moreover, an initial antibiotic change may represent treatment failure and/or lead to the development of side effects. Though dissecting this factor is challenging, an initial antibiotic change may lead to prolonged treatment duration and result in further deterioration in general condition and patient outcomes. As stated above, similar to previous reports, we conjectured that the prognostic evaluation of older patients with aspiration pneumonia requires comprehensive assessments of patient status, disease severity, and microbiological and/or antibiotic components. 
This study had some limitations. First, this was a retrospective study at a single institute. Patient characteristics and backgrounds may differ between countries and/or local regions. Thus, the generalizability of our findings to other populations may be limited. Second, the diagnosis of aspiration pneumonia was conducted based on clinical symptoms, test results compatible with pneumonia, and findings regarding aspiration assessed by the ST and trained nurse. Given the lack of consensus on diagnostic criteria for aspiration pneumonia, this issue warrants further discussion. Third, this study did not precisely investigate the cause of death, which may include mortality events other than aspiration pneumonia. Notably, unlike CAP in younger patients, some patients developed aspiration pneumonia in the course of senility and exhibited fatal outcomes. Despite these limitations, this study employed a relatively large sample size compared with previous studies on patients with aspiration pneumonia.

In conclusion, the assessment of nutrition, disease severity, microbiological findings, and antibiotic factors in older patients with aspiration pneumonia is crucial for predicting prognosis. In particular, GNRI is easy to calculate and may have a greater prognostic value than conventional nutritional indicators. Further investigations are warranted to validate the results of the present study.

\section{REFERENCES}

1. Mandell LA, Niederman MS. Aspiration pneumonia. N Engl J Med 2019;380:651-663.

2. Teramoto S, Fukuchi Y, Sasaki H, Sato K, Sekizawa K, Matsuse T. High incidence of aspiration pneumonia in community- and hospital- acquired pneumonia in hospitalized patients: a multicenter, prospective study in Japan. J Am Geriatr Soc 2008;56:577-579.

3. Metlay JP, Waterer GW, Long AC et al. Diagnosis and treatment of adults with community-acquired pneumonia. An official clinical practice guideline of the American Thoracic Society and Infectious Diseases Society of America. Am J Respir Crit Care Med 2019;200:e45-e67.

4. Torres A, Niederman MS, Chastre J et al. International ERS/ESICM/ESCMID/ALAT guidelines for the management of hospital-acquired pneumonia and ventilator-associated pneumonia: Guidelines for the management of hospital-acquired pneumonia (HAP)/ventilator-associated pneumonia (VAP) of the European Respiratory Society (ERS), European Society of Intensive Care Medicine (ESICM), European Society of Clinical Microbiology and Infectious Diseases (ESCMID) and Asociacion Latinoamericana del Torax (ALAT). Eur Respir J 2017;50:1700582.

5. The JRS guidelines for the management of pneumonia in adults 2017.

6. Okazaki T, Ebihara S, Mori T, Izumi S, Ebihara T. Association between sarcopenia and pneumonia in older people. Geriatr Gerontol Int 2020;20:7-13.

7. Agarwal E, Miller M, Yaxley A, Isenring E. Malnutrition in the elderly: a narrative review. Maturitas 2013;76:296-302.

8. de Luis D, Lopez Guzman A; Nutrition Group of Society of Castilla-Leon (Endocrinology, Diabetes and Nutrition). Nutritional status of adult patients admitted to internal medicine departments in public hospitals in Castilla y Leon, Spain - A multi-center study. Eur J Intern Med 2006;17:556-560.

9. Wallace JI, Schwartz RS, LaCroix AZ, Uhlmann RF, Pearlman RA. Involuntary weight loss in older outpatients: incidence and clinical significance. J Am Geriatr Soc 1995;43:329-337.

10. Bouillanne O, Morineau G, Dupont C et al. Geriatric Nutritional Risk Index: a new index for evaluating at-risk elderly medical patients. Am J Clin Nutr 2005;82:777-783.

11. Yajima T, Yajima K, Takahashi H. Association of the erythropoiesis-stimulating agent resistance index and the geriatric nutritional risk index with cardiovascular mortality in maintenance hemodialysis patients. PLoS One 2021;16:e245625.

12. Matsumura K, Teranaka W, Taniichi M et al. Differential effect of malnutrition between patients hospitalized with new-onset heart failure and worsening of chronic heart failure. ESC Heart Fail 2021. Doi: 10.1002/ehf2.13279 [Epub ahead of print]

13. Sonehara K, Tateishi K, Araki T, Komatsu M, Yamamoto H, Hanaoka M. Prognostic value of the geriatric nutritional risk index among patients with previously treated advanced non-small cell lung cancer who subsequently underwent immunotherapy. Thorac Cancer 2021. Doi: 10.1111/1759-7714.13909 [Epub ahead of print] 
14. Ide S, Okugawa Y, Omura Y et al. Geriatric nutritional risk index predicts cancer prognosis in patients with local advanced rectal cancer undergoing chemoradiotherapy followed by curative surgery. World J Surg Oncol 2021;19:34.

15. Xie H, Tang S, Wei L, Gan J. Geriatric nutritional risk index as a predictor of complications and longterm outcomes in patients with gastrointestinal malignancy: a systematic review and meta-analysis. Cancer Cell Int 2020;20:530.

16. Yeh CH, Wu SC, Chou SE et al. Geriatric Nutritional Risk Index as a tool to evaluate impact of malnutrition risk on mortality in adult patients with polytrauma. Int J Environ Res Public Health 2020;17:9233.

17. Wei L, Xie H, Li J et al. The prognostic value of geriatric nutritional risk index in elderly patients with severe community-acquired pneumonia: A retrospective study. Medicine 2020;99:e22217.

18. The Committee for the Japanese Respiratory Society Guidelines in the Management of Respiratory Infections. The Japanese Respiratory Society guidelines for the management of community-acquired pneumonia in adults. Respirology 2006;11:S79-S133.

19. Kanda Y. Investigation of the freely available easy-to-use software 'EZR' for medical statistics. Bone Marrow Transplant 2013;48:452-458.

20. Galkin F, Zhang B, Dmitriev SE, Gladyshev VN. Reversibility of irreversible aging. Ageing Res Rev. 2019;49:104-114.

21. Cichero J. Age-related changes to eating and swallowing impact frailty: aspiration, choking risk, modified food texture and autonomy of choice. Geriatrics 2018;3:69.

22. Ueshima J, Momosaki R, Shimizu A et al. Nutritional assessment in adult patients with dysphagia: a scoping review. Nutrients 2021;13:778.

23. Fujishima I, Fujiu-Kurachi M, Arai H et al. Sarcopenia and dysphagia: position paper by four professional organizations. Geriatr Gerontol Int 2019;19:91-97.

24. Miyazaki H, Nagata N, Akagi T et al. Comprehensive analysis of prognostic factors in hospitalized patients with pneumonia occurring outside hospital: Serum albumin is not less important than pneumonia severity assessment scale. J Infect Chemother 2018;24:602-609.

25. Hamaguchi S, Suzuki M, Sasaki K et al; Adult Pneumonia Study Group - Japan. Six underlying health conditions strongly influence mortality based on pneumonia severity in an ageing population of Japan: a prospective cohort study. BMC Pulm Med 2018;18:88.

26. Ito A, Ishida T, Tokumasu $\mathrm{H}$ et al. Prognostic factors in hospitalized community-acquired pneumonia: a retrospective study of a prospective observational cohort. BMC Pulm Med 2017;17:78.

27. Don BR, Kaysen G. Serum albumin: relationship to inflammation and nutrition. Semin Dial 2004;17:432-437.

28. Nakagawa N, Saito Y, Sasaki M, Tsuda Y, Mochizuki H, Takahashi H. Comparison of clinical profile in elderly patients with nursing and healthcare-associated pneumonia, and those with communityacquired pneumonia. Geriatr Gerontol Int 2014;14:362-371.

29. Thomsen RW, Kasatpibal N, Riis A, Norgaard M, Sorensen HT. The impact of pre-existing heart failure on pneumonia prognosis: population-based cohort study. J Gen Int Med 2008;23:1407-1413.

30. Ware LB, Matthay MA. Acute pulmonary edema. N Engl J Med 2005;353:2788-2796.

31. Heppner HJ, Sehlhoff B, Niklaus D, Pientka L, Thiem U. Pneumonie-Schwere-Index (PSI), CURB65 und Mortalitat bei hospitalisierten geriatrischen Patienten mit Aspirationspneumonie [Pneumonia Severity Index (PSI), CURB-65, and mortality in hospitalized elderly patients with aspiration pneumonia]. Z Gerontol Geriatr. 2011;44:229-234. [in German].

32. Lanspa MJ, Jones BE, Brown SM, Dean NC. Mortality, morbidity, and disease severity of patients with aspiration pneumonia. J Hosp Med 2013;8:83-90.

33. Hayashi M, Iwasaki T, Yamazaki Y et al. Clinical features and outcomes of aspiration pneumonia compared with non-aspiration pneumonia: a retrospective cohort study. J Infect Chemother 2014;20:436442 .

\section{TABLES}


Table 1. Patient characteristics

\begin{tabular}{|c|c|c|c|c|c|}
\hline & & All N (\%) & Survivor N (\%) & $\begin{array}{l}\text { Non-survivor N } \\
(\%)\end{array}$ & $\mathrm{P}$-value ${ }^{++}$ \\
\hline No. of patients & & 587 & 490 & 97 & \\
\hline Age & Years & $86 \pm 9.5^{+}$ & $85.9 \pm 9.5^{+}$ & $86.6 \pm 9.5^{+}$ & 0.42 \\
\hline Sex & Male & $358(61)$ & $289(58.9)$ & $69(71.1)$ & 0.025 \\
\hline \multirow{2}{*}{$\begin{array}{l}\text { Resident } \\
\text { location }\end{array}$} & Own home & $293(49.9)$ & $252(51.4)$ & $41(42.2)$ & 0.099 \\
\hline & Nursing home & $294(50.1)$ & $238(48.6)$ & $56(57.7)$ & \\
\hline \multirow[t]{7}{*}{ Comorbidities } & Dementia & $282(48)$ & $237(48.4)$ & $45(46.4)$ & 0.72 \\
\hline & $\begin{array}{l}\text { Stroke } \\
\text { sequelae }\end{array}$ & $90(15.3)$ & $78(15.9)$ & $12(12.4)$ & 0.44 \\
\hline & $\begin{array}{l}\text { Parkinson's } \\
\text { disease }\end{array}$ & $28(4.8)$ & $20(4.1)$ & $8(8.2)$ & 0.073 \\
\hline & $\begin{array}{l}\text { Chronic } \\
\text { respiratory } \\
\text { disease }\end{array}$ & $116(19.8)$ & $93(19)$ & $23(23.7)$ & 0.29 \\
\hline & $\begin{array}{l}\text { Chronic heart } \\
\text { failure }\end{array}$ & $91(15.5)$ & $69(14.1)$ & $22(22.7)$ & 0.033 \\
\hline & $\begin{array}{l}\text { Diabetes } \\
\text { mellitus }\end{array}$ & 108 (18.4) & $94(19.2)$ & $14(14.4)$ & 0.27 \\
\hline & Malignancy & $78(13.3)$ & $55(11.2)$ & $23(23.7)$ & $<0.001$ \\
\hline BMI & $\mathrm{kg} / \mathrm{m}^{2}$ & $18.2 \pm 3.6^{+}$ & $18.5 \pm 3.6^{+}$ & $16.4 \pm 3.6^{+}$ & $<0.001$ \\
\hline \multirow[t]{5}{*}{ GNRI } & & $83.4 \pm 12.9^{+}$ & $85 \pm 12.9^{+}$ & $75.5 \pm 12.8^{+}$ & $<0.001$ \\
\hline & $<82$ & $279(47.5)$ & $207(42.2)$ & $72(74.2)$ & $<0.001$ \\
\hline & $82[?] \mathrm{GNRI}<92$ & $172(29.3)$ & $153(31.2)$ & $19(19.6)$ & 0.021 \\
\hline & $92[?] \mathrm{GNRI}<98$ & $66(11.2)$ & $61(12.4)$ & $5(5.2)$ & 0.035 \\
\hline & {$[?] 98$} & $70(12)$ & $69(14.1)$ & $1(1)$ & $<0.001$ \\
\hline \multirow[t]{7}{*}{ A-DROP score } & & $2.4 \pm 1.1^{+}$ & $2.3 \pm 1.1^{+}$ & $2.9 \pm 1.1^{+}$ & $<0.001$ \\
\hline & 0 & $5(0.9)$ & $5(1)$ & $0(0)$ & 1.00 \\
\hline & 1 & $118(20.1)$ & $104(21.2)$ & $14(14.4)$ & 0.17 \\
\hline & 2 & $190(32.4)$ & $171(34.9)$ & $19(19.6)$ & 0.0029 \\
\hline & 3 & $193(32.9)$ & $158(32.2)$ & $35(36.1)$ & 0.46 \\
\hline & 4 & $72(12.2)$ & $49(10)$ & $23(23.7)$ & $<0.001$ \\
\hline & 5 & $9(1.5)$ & $3(0.6)$ & $6(6.2)$ & $<0.001$ \\
\hline \multirow[t]{5}{*}{$\begin{array}{l}\text { Laboratory } \\
\text { test results }\end{array}$} & $\begin{array}{l}\text { WBC, } \\
\text { cells } / \mu \mathrm{L}\end{array}$ & $10,441 \pm 5,205^{+}$ & $10,607 \pm 5,205^{+}$ & $9,607 \pm 5,219^{+}$ & 0.075 \\
\hline & $\mathrm{CRP}, \mathrm{mg} / \mathrm{dL}$ & $8.09 \pm 7.36^{+}$ & $7.96 \pm 7.36^{+}$ & $8.73 \pm 7.22^{+}$ & 0.079 \\
\hline & Albumin, $\mathrm{g} / \mathrm{dL}$ & $3.0 \pm 0.6^{+}$ & $3.1 \pm 0.6^{+}$ & $2.8 \pm 0.6^{+}$ & $<0.001$ \\
\hline & BUN, mg/dL & $22.8 \pm 13.6^{+}$ & $21.9 \pm 13.6^{+}$ & $27 \pm 13.7^{+}$ & 0.039 \\
\hline & $\begin{array}{l}\text { Creatinine, } \\
\mathrm{mg} / \mathrm{dL}\end{array}$ & $0.86 \pm 0.62^{+}$ & $0.85 \pm 0.62^{+}$ & $0.88 \pm 0.61^{+}$ & 0.56 \\
\hline \multirow{7}{*}{$\begin{array}{l}\text { First-choice } \\
\text { antibiotics }\end{array}$} & $\mathrm{ABPC} / \mathrm{SBT}$ & $499(85)$ & $423(86.3)$ & $76(78.3)$ & 0.044 \\
\hline & PIPC/TAZ & $54(9.2)$ & $40(8.2)$ & $14(14.4)$ & 0.056 \\
\hline & Carbapenem & $6(1)$ & $4(0.8)$ & $2(2.1)$ & 0.26 \\
\hline & Ceftriaxone & $10(1.7)$ & $8(1.6)$ & $2(2.1)$ & 0.67 \\
\hline & Levofloxacin & $4(0.7)$ & $3(0.6)$ & $1(1)$ & 0.52 \\
\hline & CPZ/SBT & $9(1.5)$ & $7(1.4)$ & $2(2.1)$ & 0.65 \\
\hline & Other & $5(0.8)$ & $5(1)$ & $0(0)$ & 1.00 \\
\hline
\end{tabular}




\begin{tabular}{|c|c|c|c|c|c|}
\hline & & All N (\%) & Survivor N (\%) & $\begin{array}{l}\text { Non-survivor N } \\
(\%)\end{array}$ & P-value ${ }^{++}$ \\
\hline $\begin{array}{l}\text { Administration } \\
\text { period, days }\end{array}$ & & $10.8 \pm 6.6^{+}$ & $10 \pm 6.6^{+}$ & $14.5 \pm 6.7^{+}$ & $<0.001$ \\
\hline $\begin{array}{l}\text { Switching } \\
\text { antibiotic }\end{array}$ & & $112(19.1)$ & $71(14.5)$ & $41(42.3)$ & $<0.001$ \\
\hline \multirow[t]{2}{*}{ Clinical course } & $\begin{array}{l}\text { Length of stay, } \\
\text { days }\end{array}$ & $29.9 \pm 24^{+}$ & $28.8 \pm 24^{+}$ & $35.7 \pm 24.1^{+}$ & 0.0046 \\
\hline & $\begin{array}{l}\text { In-hospital } \\
\text { mortality }\end{array}$ & $97(16.5)$ & & & \\
\hline
\end{tabular}

+ Mean \pm standard deviation

++ Comparison between "survivor" and "non-survivor" group

Abbreviations: BMI, body mass index; GNRI, geriatric nutritional risk index; NE, not evaluated; WBC, white blood cell; CRP, C-reactive protein; BUN, blood urea nitrogen; ABPC/SBT, ampicillin/sulbactam; PIPC/TAZ, piperacillin/tazobactam; CTRX, ceftriaxone; CPZ/SBT, cefoperazone/sulbactam.

Table 2. Microbiological findings

\begin{tabular}{|c|c|c|c|c|}
\hline & All N(\%) & Survivor N(\%) & Non-survivor $\mathrm{N}(\%)$ & P-value ${ }^{+}$ \\
\hline No. of patients & 521 & 437 & 84 & \\
\hline $\begin{array}{l}\text { Streptococcus } \\
\text { pneumoniae }\end{array}$ & $42(8.1)$ & $32(7.3)$ & $10(11.9)$ & 0.19 \\
\hline \multicolumn{5}{|l|}{$\begin{array}{l}\text { Staphylococcus } \\
\text { aureus }\end{array}$} \\
\hline MSSA & $106(20.4)$ & $88(20.1)$ & $18(21.4)$ & 0.77 \\
\hline MRSA & $66(12.7)$ & $54(12.4)$ & $12(14.3)$ & 0.59 \\
\hline $\begin{array}{l}\text { Pseudomonas } \\
\text { aeruginosa }\end{array}$ & $51(9.8)$ & $43(9.8)$ & $8(9.5)$ & 1.00 \\
\hline $\begin{array}{l}\text { Klebsiella } \\
\text { pneumoniae }\end{array}$ & $76(14.6)$ & $61(14)$ & $15(17.9)$ & 0.40 \\
\hline $\begin{array}{l}\text { Haemophilus } \\
\text { influenzae }\end{array}$ & $20(3.8)$ & $15(3.4)$ & $5(6)$ & 0.35 \\
\hline $\begin{array}{l}\text { Moraxella } \\
\text { catarrhalis }\end{array}$ & $27(5.2)$ & $21(4.8)$ & $6(7.1)$ & 0.42 \\
\hline Escherichia coli & $44(8.5)$ & $37(8.5)$ & $7(8.3)$ & 1.00 \\
\hline Enterobactor spp. & $37(7.1)$ & $31(7.1)$ & $6(7.1)$ & 1.00 \\
\hline $\begin{array}{l}\text { Serratia } \\
\text { marcescens }\end{array}$ & $14(2.7)$ & $13(3)$ & $1(1.2)$ & 0.71 \\
\hline Proteus mirabilis & $13(2.5)$ & $11(2.5)$ & $2(2.3)$ & 1.00 \\
\hline $\begin{array}{l}\text { Acinetobacter } \\
\text { baumanii }\end{array}$ & $11(2.1)$ & $10(2.3)$ & $1(1.2)$ & 1.00 \\
\hline $\begin{array}{l}\text { Stenotrophomonas } \\
\text { maltophilia }\end{array}$ & $4(0.8)$ & $4(0.9)$ & $0(0)$ & 1.00 \\
\hline ESBLs & $24(4.6)$ & $21(4.8)$ & $3(3.6)$ & 0.78 \\
\hline PDR pathogens & $156(29.9)$ & $132(30.2)$ & $24(28.6)$ & 0.80 \\
\hline
\end{tabular}

+ Comparison between "survivor" and "non-survivor" group 
Abbreviations: MSSA, methicillin-sensitive Staphylococcus aureus ; MRSA, methicillin-resistant Staphylococcus aureus ; ESBL, extended-spectrum $\beta$-lactamase; PDR, potentially drug resistance.

Table 3. Logistic regression analysis for in-hospital mortality

\begin{tabular}{|c|c|c|c|c|c|c|}
\hline & Univariate & Univariate & Univariate & Multivariate & Multivariate & Multivariate \\
\hline Variables & OR & $95 \%$ CI & $\mathrm{P}$-value & OR & $95 \%$ CI & P-value \\
\hline Age & 1.01 & $0.98-1.04$ & 0.42 & 1.02 & $0.99-1.06$ & 0.18 \\
\hline Male gender & 1.71 & $1.07-2.75$ & 0.026 & 1.88 & $1.07-3.31$ & 0.028 \\
\hline $\begin{array}{l}\text { Resident } \\
\text { location Own } \\
\text { home vs. } \\
\text { nursing home }\end{array}$ & 1.43 & $0.93-2.25$ & 0.10 & 1.22 & $0.73-2.04$ & 0.44 \\
\hline $\begin{array}{l}\text { Dementia } \\
\text { With vs. } \\
\text { without }\end{array}$ & 0.92 & $0.60-1.43$ & 0.72 & & & \\
\hline $\begin{array}{l}\text { Stroke } \\
\text { sequelae With } \\
\text { vs. without }\end{array}$ & 0.75 & $0.39-1.43$ & 0.38 & & & \\
\hline $\begin{array}{l}\text { Parkinson's } \\
\text { disease With } \\
\text { vs. without }\end{array}$ & 2.11 & $0.90-4.95$ & 0.085 & & & \\
\hline $\begin{array}{l}\text { Chronic heart } \\
\text { failure With } \\
\text { vs. without }\end{array}$ & 1.79 & $1.04-3.07$ & 0.034 & 2.14 & $1.11-4.12$ & 0.023 \\
\hline $\begin{array}{l}\text { Chronic } \\
\text { respiratory } \\
\text { disease With } \\
\text { vs. without }\end{array}$ & 1.33 & $0.79-2.33$ & 0.29 & & & \\
\hline $\begin{array}{l}\text { Diabetes } \\
\text { mellitus With } \\
\text { vs. without }\end{array}$ & 0.71 & $0.39-1.31$ & 0.27 & & & \\
\hline $\begin{array}{l}\text { Malignancy } \\
\text { With vs. } \\
\text { without }\end{array}$ & 2.46 & $1.42-4.24$ & 0.0012 & 2.66 & $1.41-5.00$ & 0.0025 \\
\hline WBC & 0.99 & $0.99-1.00$ & 0.078 & & & \\
\hline $\mathrm{CRP}$ & 1.01 & $0.99-1.04$ & 0.35 & & & \\
\hline Albumin & 0.35 & $0.24-0.53$ & $<0.001$ & 1.93 & $0.85-4.34$ & 0.11 \\
\hline BUN & 1.02 & $1.01-1.04$ & $<0.001$ & & & \\
\hline Creatinine & 1.09 & $0.75-1.58$ & 0.65 & & & \\
\hline A-DROP & 1.76 & $1.4-2.21$ & $<0.001$ & 1.48 & $1.16-1.90$ & 0.002 \\
\hline GNRI & 0.94 & $0.92-0.95$ & $<0.001$ & 0.91 & $0.87-0.95$ & $<0.001$ \\
\hline $\begin{array}{l}\text { Antibiotic } \\
\text { change With } \\
\text { vs. without }\end{array}$ & 4.32 & $2.69-6.95$ & $<0.001$ & 4.22 & $2.48-7.19$ & $<0.001$ \\
\hline
\end{tabular}

$\mathrm{N}=587$, including 97 mortality events

Abbreviations: OR, odds ratio; CI, confidence interval; WBC, white blood cell; CRP; C-reactive protein; BUN, blood urea nitrogen; BMI, body mass index; GNRI, geriatric nutritional risk index.

FIGURE LEGENDS 
Figure 1. Process of patient inclusion and exclusion. GNRI; geriatric nutritional risk index.

Figure 2. Receiver operating characteristic curves and comparison of predictive values for in-hospital mortality. Area under the curve (AUC) of geriatric nutritional risk index (GNRI) was greater than that of albumin (A), A-DROP (B), and body mass index (BMI) (C), with a significant difference compared with albumin.

\section{Hosted file}

AP_Figure_Re.pptx available at https://authorea.com/users/412671/articles/521272-prognosticvalue-of-geriatric-nutritional-risk-index-for-aspiration-pneumonia-a-retrospective-study 